\title{
Cue competition in causality judgments: The role of manner of information presentation
}

\author{
LINDA J. VAN HAMME and EDWARD A. WASSERMAN \\ University of Iowa, Iowa City, Iowa
}

\begin{abstract}
College students rated the causal efficacy of elements $\mathrm{X}, \mathrm{A}$, and $\mathrm{B}$ of food compounds $\mathrm{AX}$ and BX in producing the allergic reaction of a hypothetical patient. Causal ratings were made for each food after subjects received all of the results of a 16-day allergy test. With both serial and simultaneous presentation of information, ratings of distinctive elements $A$ and $B$ diverged and ratings of common element $\mathrm{X}$ decreased as the difference between the correlation of $\mathrm{AX}$ and $\mathrm{BX}$ with the allergic reaction increased. These human diagnostic judgments closely correspond with stimulus selection effects observed in the conditioned responses of animals in associative learning studies.
\end{abstract}

The Rescorla-Wagner model, as well as other theories of conditioning (e.g., those of Mackintosh, 1975, and Pearce \& Hall, 1980), were developed to provide an explanation of the selective nature of conditioning disclosed by such phenomena as blocking, overshadowing, and conditioned inhibition. Rescorla and Wagner (1972) argued that a reinforcer will sustain only a limited amount of associative strength; therefore, simultaneously presented cues compete for association with an outcome.

Several researchers have proposed that selectional processes in human causality judgments can also be described by associative models like that of Rescorla and Wagner (Chapman, 1991; Chapman \& Robbins, 1990; Gluck \& Bower, 1988; Shanks, 1986, 1989; Shanks \& Dickinson, 1987; Wasserman, 1990a, 1990b). These workers have attempted to evaluate this proposal by seeking empirical convergence between the results of animal associative learning studies and investigations of complex human judgment. They have obtained evidence that suggests the presence of cue competition due to blocking, overshadowing, or conditioned inhibition in human contingency judgment and causal or diagnostic inference (Algom \& Bizman, 1983; Chapman, 1991; Chapman \& Robbins, 1990; Dickinson, Shanks, \& Evenden, 1984; Gluck \& Bower, 1988; Shanks, 1986, 1989).

Wasserman (1990a) provided one such example of stimulus competition in human causality judgments in an experimental procedure modeled on work originally done by Wagner, Logan, Haberlandt, and Price (1968) and later extended by Wasserman (1974) involving animal Pavlovian and operant conditioning procedures. In the animal research, the amount of conditioned responding to one element $(\mathrm{X})$ of a compound stimulus depended on the differential predictiveness of two other stimuli (A or B) with which $\mathrm{X}$ was concurrently presented, even though the

Correspondence concerning this article should be addressed to $\mathrm{E}$. A. Wasserman, Department of Psychology, University of Iowa, lowa City, IA 52242. correlation of stimulus $\mathrm{X}$ with the outcome remained the same in all experimental conditions. The human subjects in Wasserman's (1990a) study were given the task of diagnosing the source of a hypothetical patient's allergic reaction. College students judged the causal efficacy of common (X) and distinctive (A or B) elements (food items) of the compound stimuli $\mathrm{AX}$ and $\mathrm{BX}$. As the difference between the correlations of $\mathrm{AX}$ and $\mathrm{BX}$ with the occurrence and nonoccurrence of the allergic reaction increased from .00 to 1.00 , ratings of the common $\mathrm{X}$ element decreased, even though the correlation of $X$ with the allergic reaction remained at .50 in all experimental conditions. These human causal judgments thus exhibited selective effects parametrically parallel to those seen in the conditioned responses of the animals in the associative learning studies of Wagner et al. (1968) and Wasserman (1974).

Wasserman's (1990a) study involved two methods of information presentation: (1) a $2 \times 2$ summary table and (2) a serial listing of the individual trials. Both of these procedures involved the simultaneous presentation of all contingency information. Shanks (1991; Shanks \& Dickinson, 1987) has proposed, however, that associative models of causal judgments are only applicable to experienced situations that involve temporally distributed events and presentation of information on a trial-by-trial basis, which allows the incrementing of associative connections. He suggested that associative accounts cannot be offered for judgments based on described events or summary tables of event co-occurrence. Shanks (1991) proposed that the two types of judgment utilize similar information, but different psychological mechanisms for processing that information.

One of our purposes in the present experiment was to compare causal judgments with experienced (trial-by-trial) versus described (summarized) information about the covariation between outcomes and potential causes. Before attempting to evaluate Shanks's multiple-mechanism account of causal judgments, it seems desirable to seeideally, in the same experiment-whether similar results 
are actually obtained with both types of procedure. These two methods of presenting contingency information have been explicity compared in only a few experiments, with conflicting results. Ward and Jenkins (1965) found that subjects were much more accurate in judging interevent contingencies when information was presented in summary rather than serial form. Baker, Berbrier, and ValleeTourangeau (1989) reported, however, that subjects assessed interevent contingencies at the same accuracy level with both types of presentation format.

In addition to their conflicting results, these previous efforts to compare trial-by-trial and summarized information presentation have not concerned the selective nature of contingency or causality judgments, in which cue competition occurs among multiple possible causes of an effect. The earlier studies involved only the assessment of the degree of covariation between the making of a particular response and the observation of a particular outcome. We designed the present experiment to compare these two methods of information presentation in the context of cue competition.

Subjects were asked to rate the likelihood that three different foods were the cause of an allergic reaction in a hypothetical patient. Three experimental conditions varied the differential correlations $(.00, .50$, and 1.00$)$ of food $\mathrm{A}$ and food X (AX) and food B and food X (BX) combinations with the occurrence and nonoccurrence of the allergic reaction. The three conditions were presented in both a trial-by-trial (TT) and a serial-list (SL) format. A mixed design was used, with format and differential contingency $(\mathrm{AX}-\mathrm{BX})$ as within-subjects factors and order of presentation of the formats as the between-subjects factor.

\section{METHOD}

\section{Subjects}

The subjects were 108 University of Iowa undergraduates in an introductory psychology course, who participated in the study in partial fulfillment of a course requirement.

\section{Materials}

Twelve versions of the experimental sheets were prepared, corresponding with the different combinations of: (1) three levels of differential correlation of the food compounds $(\mathrm{AX}-\mathrm{BX})$ with the allergic reaction, (2) two different presentation formats, and (3) two different sets of foods corresponding with the $\mathrm{A}, \mathrm{B}$, and $\mathrm{X}$ items for each contingency. Each subject received six sheets. All sheets began with the following instructions:

Imagine that you are an allergist who is trying to determine the cause of an allergic reaction shortly after your patient eats dinner. You arrange that the patient eat particular foods at dinner over a series of evenings, and then report to you whether an allergic reaction followed.

The instructions for the serial-list format continued as follows:

The results of the test series are shown below:

The instructions for the trial-by-trial format continued as follows:

The results of the test series will be shown to you on a set of slides. There will be one slide for each day of the allergy test. Each slide will indicate what the patient ate for dinner that day and whether there was an allergic reaction.

In the SL format, the results were displayed in 16 rows, representing the occurrence and type of Food 1, Food 2, and Food 3 and whether or not an allergic reaction had occurred on each day of the 16-day test series. In the TT format, the results were presented on 16 separate slides, with each slide corresponding with and displaying the same information as one row of the serial list. Food 1 was eaten every day; either Food 2 or Food 3 was eaten together with Food 1 on a random half of the days. Food 2 + Food 1 combinations were considered AX compounds; Food $3+$ Food 1 combinations were considered BX compounds. No compound was listed more than twice in a row.

The order of occurrence of the AX and BX compounds and the occurrence or nonoccurrence of an allergic reaction over the hypothetical test series, which were identical for the SL and TT formats, are shown in Table 1. The experimental conditions, $\mathrm{AX}-\mathrm{BX}$ of $.00, .50$, and 1.00 , were defined by the difference in the probability of an allergic reaction (R) after the different two-food combinations, AX and BX $[P(\mathrm{R} \mid \mathrm{AX})-P(\mathrm{R} \mid \mathrm{BX})]$.

Following receipt of the results of the allergy test series in either presentation format, the subjects were asked to indicate their diagnosis of the allergic reaction by choosing the appropriate number along each of three rating scales: one each for Food 1, Food 2, and Food 3. Each scale ranged from 0 to 8 , with the following verbal descriptions at selected points along the scale: 0 , definitely not; 4 , possibly; and 8 , definitely the cause of the allergic reaction.

\section{Procedure}

The 108 participants were divided into 12 groups with $7-10$ subjects in each; variability in group size was due to the vicissitudes of scheduling the subjects. Each subject in all groups was given six of the experimental sheets and made causal ratings of the three foods in each of the three AX - BX conditions in each of the two presentation formats. Different foods were used on each of the six rating sheets. Groups 1-6 rated the three differential contingencies in the SL format first and then rated the three contingencies in the TT format; this order was reversed for Groups 7-12. The order of presentation of the AX BX conditions and the food types was varied across groups, such that all possible combinations of these orders were presented in Groups 1-6 and in Groups 7-12. Table 2 shows a summary of the experimental procedures, and Table 3 shows the foods used in each condition.

\section{RESULTS}

Figure 1A shows the mean causal ratings of elements $\mathrm{X}, \mathrm{A}$, and $\mathrm{B}$ for all groups combined as a function of the differential AX - BX correlation for the SL format; Figure 1B depicts the same functions for the TT format. Increases in the $\mathrm{AX}-\mathrm{BX}$ correlation produced increases in the judged causal efficacy of element $A$ and decreases

Table 1

Order of Occurrence of $\mathbf{A X}$ and $\mathrm{BX}$ Compounds and Allergic Reactions for the Three Different AX - BX Correlations

\begin{tabular}{ccccc}
\hline & & \multicolumn{3}{c}{ AX - BX } \\
\cline { 3 - 5 } Trial & $\begin{array}{c}\text { Stimulus } \\
\text { Compound }\end{array}$ & .00 & \multicolumn{3}{c}{.0 } & 1.00 \\
\hline 1 & AX & yes & yes & yes \\
2 & BX & no & no & no \\
3 & BX & yes & yes & no \\
4 & AX & no & yes & yes \\
5 & AX & no & no & yes \\
6 & BX & yes & no & no \\
7 & AX & yes & yes & yes \\
8 & BX & no & no & no \\
9 & BX & yes & yes & no \\
10 & AX & no & yes & yes \\
11 & BX & no & no & no \\
12 & AX & yes & yes & yes \\
13 & AX & no & no & yes \\
14 & BX & yes & no & no \\
15 & AX & yes & yes & yes \\
16 & BX & no & no & no \\
\hline
\end{tabular}


Table 2

Order of Presentation of Experimental Conditions in Groups 1-12

\begin{tabular}{|c|c|c|c|c|c|c|c|c|}
\hline \multirow{2}{*}{$\frac{\text { Group }}{1}$} & \multirow{2}{*}{$\frac{n}{9}$} & \multirow{2}{*}{$\begin{array}{c}\begin{array}{c}\text { Format } \\
\text { Order }\end{array} \\
\text { SL } \\
\text { TT }\end{array}$} & \multicolumn{3}{|c|}{$\begin{array}{c}\mathbf{A X}-\mathbf{B X} \\
\text { Condition } \\
\text { Order }\end{array}$} & \multicolumn{3}{|c|}{$\begin{array}{c}\text { Food } \\
\text { Condition } \\
\text { Order }\end{array}$} \\
\hline & & & $\begin{array}{l}.50 \\
.50\end{array}$ & $\begin{array}{r}1.00 \\
.00\end{array}$ & $\begin{array}{r}.00 \\
1.00\end{array}$ & $\begin{array}{l}5 \\
2\end{array}$ & $\begin{array}{l}6 \\
1\end{array}$ & $\begin{array}{l}4 \\
3\end{array}$ \\
\hline 2 & 10 & $\begin{array}{l}\text { SL } \\
\text { TT }\end{array}$ & $\begin{array}{l}.00 \\
.00\end{array}$ & $\begin{array}{r}.50 \\
1.00\end{array}$ & $\begin{array}{r}1.00 \\
.50\end{array}$ & $\begin{array}{l}4 \\
1\end{array}$ & $\begin{array}{l}5 \\
3\end{array}$ & $\begin{array}{l}6 \\
2\end{array}$ \\
\hline 3 & 9 & $\begin{array}{l}\text { SL } \\
\text { TT }\end{array}$ & $\begin{array}{l}1.00 \\
1.00\end{array}$ & $\begin{array}{l}.00 \\
.50\end{array}$ & $\begin{array}{l}.50 \\
.00\end{array}$ & $\begin{array}{l}6 \\
3\end{array}$ & $\begin{array}{l}4 \\
2\end{array}$ & $\begin{array}{l}5 \\
1\end{array}$ \\
\hline 4 & 10 & $\begin{array}{l}\text { SL } \\
\text { TT }\end{array}$ & $\begin{array}{l}.50 \\
.50\end{array}$ & $\begin{array}{r}.00 \\
1.00\end{array}$ & $\begin{array}{r}1.00 \\
.00\end{array}$ & $\begin{array}{l}2 \\
5\end{array}$ & $\begin{array}{l}1 \\
6\end{array}$ & $\begin{array}{l}3 \\
4\end{array}$ \\
\hline 5 & 8 & $\begin{array}{l}\text { SL } \\
\text { TT }\end{array}$ & $\begin{array}{l}.00 \\
.00\end{array}$ & $\begin{array}{r}1.00 \\
.50\end{array}$ & $\begin{array}{r}.50 \\
1.00\end{array}$ & $\begin{array}{l}1 \\
4\end{array}$ & $\begin{array}{l}3 \\
5\end{array}$ & $\begin{array}{l}2 \\
6\end{array}$ \\
\hline 6 & 9 & $\begin{array}{l}\text { SL } \\
\text { TT }\end{array}$ & $\begin{array}{l}1.00 \\
1.00\end{array}$ & $\begin{array}{l}.50 \\
.00\end{array}$ & $\begin{array}{l}.00 \\
.50\end{array}$ & $\begin{array}{l}3 \\
6\end{array}$ & $\begin{array}{l}2 \\
4\end{array}$ & $\begin{array}{l}1 \\
5\end{array}$ \\
\hline 7 & 10 & $\begin{array}{l}\text { TT } \\
\text { SL }\end{array}$ & $\begin{array}{l}.50 \\
.50\end{array}$ & $\begin{array}{r}.00 \\
1.00\end{array}$ & $\begin{array}{r}1.00 \\
.00\end{array}$ & $\begin{array}{l}2 \\
5\end{array}$ & $\begin{array}{l}1 \\
6\end{array}$ & $\begin{array}{l}3 \\
4\end{array}$ \\
\hline 8 & 10 & $\begin{array}{l}\text { TT } \\
\text { SL }\end{array}$ & $\begin{array}{l}.00 \\
.00\end{array}$ & $\begin{array}{r}1.00 \\
.50\end{array}$ & $\begin{array}{r}.50 \\
1.00\end{array}$ & $\begin{array}{l}1 \\
4\end{array}$ & $\begin{array}{l}3 \\
5\end{array}$ & $\begin{array}{l}2 \\
6\end{array}$ \\
\hline 9 & 7 & $\begin{array}{l}\text { TT } \\
\text { SL }\end{array}$ & $\begin{array}{l}1.00 \\
1.00\end{array}$ & $\begin{array}{l}.50 \\
.00\end{array}$ & $\begin{array}{l}.00 \\
.50\end{array}$ & $\begin{array}{l}3 \\
6\end{array}$ & $\begin{array}{l}2 \\
4\end{array}$ & $\begin{array}{l}1 \\
5\end{array}$ \\
\hline 10 & 7 & $\begin{array}{l}\text { TT } \\
\text { SL }\end{array}$ & $\begin{array}{l}.50 \\
.50\end{array}$ & $\begin{array}{r}1.00 \\
.00\end{array}$ & $\begin{array}{r}.00 \\
1.00\end{array}$ & $\begin{array}{l}5 \\
2\end{array}$ & $\begin{array}{l}6 \\
1\end{array}$ & $\begin{array}{l}4 \\
3\end{array}$ \\
\hline 11 & 9 & $\begin{array}{l}\text { TT } \\
\text { SL }\end{array}$ & $\begin{array}{l}.00 \\
.00\end{array}$ & $\begin{array}{r}.50 \\
1.00\end{array}$ & $\begin{array}{r}1.00 \\
.50\end{array}$ & $\begin{array}{l}4 \\
1\end{array}$ & $\begin{array}{l}5 \\
3\end{array}$ & $\begin{array}{l}6 \\
2\end{array}$ \\
\hline 12 & 10 & $\begin{array}{l}\text { TT } \\
\text { SL }\end{array}$ & $\begin{array}{l}1.00 \\
1.00\end{array}$ & $\begin{array}{l}.00 \\
.50\end{array}$ & $\begin{array}{l}.50 \\
.00\end{array}$ & $\begin{array}{l}6 \\
3\end{array}$ & $\begin{array}{l}4 \\
2\end{array}$ & $\begin{array}{l}5 \\
1\end{array}$ \\
\hline
\end{tabular}

in the ratings of elements $\mathrm{B}$ and $\mathrm{X}$ in both presentation formats. Three 2 (format) $\times 2$ (order) $\times 3$ (correlation) analyses of variance for elements X, A, and B were conducted to assess these trends statistically.

No differences were found for format or for the order of format presentation in any of the analyses. The correlation factor for element $A$ was significant $[F(2,636)=$ $607.35, p<.001]$, indicating that the increase in ratings of element A was reliable. The only other significant result for element A was the format by correlation interaction $[F(2,636)=3.67, p<.05]$. Simple-effects follow-ups revealed the increase to be reliable for both SL and TT formats $[F(2,636)=295.78, p<.001$, and $F(2,636)=308.64, p<.001$, respectively]. The correlation factor was also significant for element $\mathrm{B}[F(2,636)=$ $550.39, p<.001]$, indicating that the decrease in ratings of element B was reliable. No interactions were significant. The only significant effect for element $\mathrm{X}$ was the correlation factor $[F(2,636)=64.59, p<.001]$, indicating that the decrease in ratings for element $\mathrm{X}$ was reliable.

Table 3

Food Conditions

\begin{tabular}{cclll}
\hline Food & & \multicolumn{3}{c}{ Stimulus Element } \\
\cline { 4 - 5 } Condition & AX - BX & \multicolumn{1}{c}{$\mathrm{X}$} & \multicolumn{1}{c}{ A } & \multicolumn{1}{c}{ B } \\
\hline 1 & .00 & shrimp & strawberries & peanuts \\
2 & .50 & yogurt & bran & cabbage \\
3 & 1.00 & bananas & chicken & mustard \\
4 & .00 & wheat & walnuts & peaches \\
5 & .50 & corn & horseradish & lobster \\
6 & 1.00 & blueberries & cheese & pork \\
\hline
\end{tabular}

\section{DISCUSSION}

As in Wasserman's (1990a) study, these results demonstrate both a qualitative and a quantitative correspondence between humans' causal judgments and animals' conditioned responses. Although the actual correlation of element $X$ with the allergic reaction did not change across the three AX - BX correlations, the perceived causal efficacy of element $\mathrm{X}$ decreased as element $\mathrm{A}$ became a more reliable predictor of the allergic reaction and element $\mathrm{B}$ became a more reliable predictor of its nonoccurrence. This effect was reliably obtained regardless of whether the information was described to subjects in a summarized manner or experienced trial-by-trial.

This empirical parallel-observed for the first time here in a withinsubjects procedure-does not, of course, demonstrate conclusively that the same associative mechanisms are involved in both types of judgment. As Shanks (1991) has noted, similar results do not necessarily implicate similar mechanisms; different processes may be sensitive to the same types of evidence. Yet, to say that a judgment based on summarized evidence cannot logically be produced in the immediate situation through an incremental process is not equivalent to saying that such a judgment does not result in any way from the associative learning mechanisms of instrumental or classical conditioning. The former statement is undeniably accurate; the latter has yet to be demonstrated.

According to Shanks's explanation (see also Cheng \& Holyoak, 1985; Shanks \& Dickinson, 1987), in situations that have been experienced, an associative mechanism operates to create specific causal beliefs. Described situations result in either the retrieval and application of relevant specific beliefs or the reliance on "metabeliefs" about causality. Causal metabeliefs are said to be abstracted in some manner from experienced situations and to involve such factors as temporal precedence, contiguity, necessity, sufficiency, and counterfactual relations. These abstract rules and beliefs are said not to require an associative mechanism for their development or application.

In our opinion, the argument that the utilization and development of abstract rules and beliefs does not require an associative mechanism fails to address the more basic question of how these rules are abstracted from experienced situations, for the associative mechanism is said to 
(A)

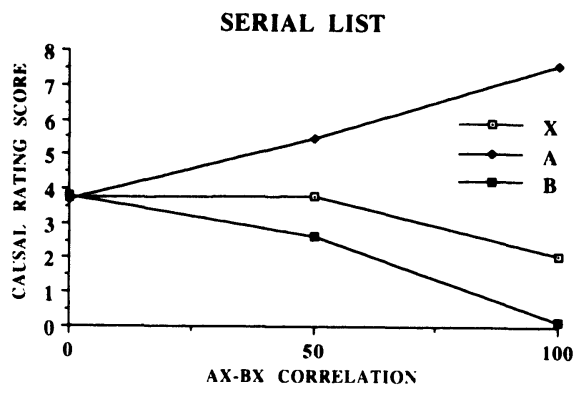

(B)

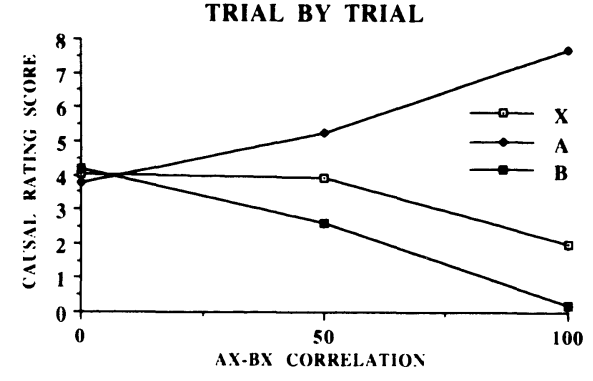

Figure 1. (A) Mean causal rating scores of subjects in all groups combined for the serial list format to elements $A, B$, and $X$ of $A X$ and $B X$ compounds as a function of the difference in the predictiveness of those compounds (AX - BX) for the occurrence of an allergic reaction. (B) Mean causal rating scores of subjects in all groups combined for the trial-by-trial format to elements $A, B$, and $X$ of $A X$ and $B X$ compounds as a function of the difference in the predictiveness of those compounds $(\mathrm{AX}-\mathrm{BX})$ for the occurrence of an allergic reaction.

create only specific causal beliefs. The judgment and problem-solving activities involved in causal inferences about described situations obviously require the abilities of humans to acquire and manipulate verbal and symbolic information. However, Shanks's proposal that causal judgments about described situations cannot result from an associative process seems to be based on more than the necessity of presenting such information in a verbal format. The further assumption is made that the abstraction of rules and beliefs from temporally experienced events cannot result from an associative mechanism.

This further assumption can be contradicted, however, by noting that the causal rules such as contiguity, temporal precedence, necessity, and sufficiency, described by Shanks (1991) as nonassociative metabeliefs, also represent the conditions necessary for classical and instrumental learning by animals. The temporal precedence of the conditioned stimulus and its contiguity with the unconditioned stimulus are hallmarks of the procedures necessary for classical conditioning to occur. And stimulus selection effects such as blocking, overshadowing, and latent inhibition, in both classical and instrumental conditioning, represent evident conditioning failures due to failures of necessity or sufficiency. Few would argue that these results are due to nonassociative processes or that they require the conscious application of causal rules.

The purpose of the present experiment was to explore the plausibility of associative accounts as general models of causality judgment relevant to both described and experienced situations. The similarity of the stimulus selection effects observed with simultaneous and serial pre- sentation of contingency information suggests that the causal rules used by subjects to make judgments about described, summarized information were derived through the operation of an associative mechanism during previous experience with temporally distributed events.

\section{REFERENCES}

Algom, D., \& Bizman, A. (1983). Attribution theory: A conditioning interpretation. Perceptual \& Motor Skills, 56, 767-774.

Baker, A. G., Berbrier, M. W., \& Vallee-Tourangeau, F. (1989). Judgments of a $2 \times 2$ contingency table: Sequential processing and the learning curve. Quarterly Journal of Experimental Psychology, 41B, 65-97.

Chapman, G. B. (1991). Trial order affects cue interaction in contingency judgment. Journal of Experimental Psychology: Learning, Memory, \& Cognition, 17, 837-854.

Chapman, G. B., \& Robbins, S. J. (1990). Cue interaction in human contingency judgment. Memory \& Cognition, 18, 537-545.

Cheng, P. W., \& Holyoak, K. J. (1985). Pragmatic reasoning schemas. Cognitive Psychology, 17, 391-416.

Dickinson, A., Shanks, D., \& Evenden, J. (1984). Judgment of actoutcome contingency: The role of selective attribution. Quarterly Journal of Experimental Psychology, 36A, 29-50.

Gluck, M. A., \& Bower, G. H. (1988). From conditioning to category learning: An adaptive network model. Journal of Experimental Psychology: General, 117, 227-247.

Mackintosh, N. J. (1975). A theory of attention: Variations in the associability of stimuli with reinforcement. Psychological Review, 82, 276-298.

Pearce, J. M., \& Hall, G. (1980). A model for Pavlovian learning: Variations in the effectiveness of conditioned but not of unconditioned stimuli. Psychological Review, 87, 532-552.

Rescorla, R. A., \& Wagner, A. R. (1972). A theory of Pavlovian conditioning: Variations in the effectiveness of reinforcement and nonreinforcement. In A. H. Black \& W. F. Prokasy (Eds.), Classical conditioning II: Current research and theory (pp. 64-99). New York: Appleton-Century-Crofts.

ShanKs, D. R. (1986). Selective attribution and the judgment of causality. Learning \& Motivation, 17, 311-334.

Shanks, D. R. (1989). Selectional processes in causality judgment. Memory \& Cognition, 17, 27-34.

Shanks, D. R. (1991). On similarities between causal judgments in experienced and described situations. Psychological Science, 2, 1-10.

Shanks, D. R., \& Dickinson, A. (1987). Associative accounts of causality judgment. In G. H. Bower (Ed.), The psychology of learning and motivation (pp. 229-261). New York: Academic Press.

Wagner, A. R., Logan, F. A., Haberlandt, K., \& Price, T. (1968). Stimulus selection in animal discrimination learning. Journal of Experimental Psychology, 76, 171-180.

WARD, W. C., \& JENKINS, H. M. (1965). The display of information and the judgment of contingency. Canadian Journal of Psychology, 19, 231-241.

WASSERMAN, E. A. (1974). Stimulus-reinforcer predictiveness and selective discrimination learning in pigeons. Journal of Experimental Psychology, 103, 284-297.

Wasserman, E. A. (1990a). Attribution of causality to common and distinctive elements of compound stimuli. Psychological Science, 1, 298-302.

Wasserman, E. A. (1990b). Detecting response-outcome relations: Toward an understanding of the causal texture of the environment. In G. H. Bower (Ed.), The psychology of learning and motivation (pp. 27-82). New York: Academic Press.

(Manuscript received May 15, 1993.) 